\title{
Rationale for a Stronger Disposition of Chardonnay Wines for Stuck and Sluggish Fermentation
}

\author{
S. Sommer ${ }^{*}$, P. Wegmann-Herr², M. Wacker ${ }^{2}$, U. Fischer ${ }^{2}$ \\ (1) Appalachian State University, Fermentation Sciences, 730 Rivers St., Boone, NC 28607 \\ (2) Competence Center for Wine Research (DLR - Rheinpfalz), Breitenweg 71, 67435 Neustadt/Weinstraße, Germany
}

Submitted for publication: September 2014

Accepted for publication: December 2014

Key words: Chardonnay, stuck fermentation, fatty acids, amino acids, mineral compounds

\begin{abstract}
The aim of this study was to identify and evaluate factors that contribute to fermentation problems in Chardonnay, since this variety is reported to have frequent problems. Analytical methods included gas chromatography mass spectrometry, as well as atomic absorption spectroscopy and FT-MIR spectroscopy. Chardonnay, Pinot blanc, Pinot noir and Pinot noir précoce were screened to relate observations to specific varietal properties. The results show a significant distinction in the amino acid profile of Chardonnay, which can be correlated with sluggish fermentation. A comparison between the fatty acid profile of Chardonnay and Pinot blanc reveals that Chardonnay contains more toxic compounds, which inhibit yeast metabolism. Mineral supply and potential metal toxicity were also analysed. The concentrations of iron, copper, magnesium, zinc and manganese show significant variations among the grape varieties. In conclusion, the possible causes for stuck fermentation in Chardonnay could be more related more to variety than to oenological decisions.
\end{abstract}

\section{INTRODUCTION}

Sluggish and stuck fermentations are still a major cause of serious economic losses for wine producers, as most wines cannot be marketed successfully with residual sugar. Furthermore, inactive yeast may stimulate the proliferation of lactic acid bacteria, which can form undesired compounds like acetic acid and ethyl acetate from the glucose and fructose present in stuck fermentations (Lafon-Lafourcade et al., 1984). A commercial alcoholic fermentation should be finished between five days for red wines and up to three weeks for white wines, depending on temperature, selected yeast strain and nutritional status of the grape juice. In case of sluggish fermentations, this period may increase to several months (Bisson, 1999). In this case, special measures have to be taken to prevent detrimental oxidation, as the reducing potential of the yeast vanishes with inactive and settling yeast (Fischer, 2000).

Fermentation problems usually originate due to a combination of several factors, which is more inhibiting than the occurrence of a single factor alone (Bisson, 1999). Some stressors, such as ethanol, cannot be avoided during vinification, but others are a result of avoidable oenological shortcomings (Malherbe et al., 2007). Stuck or sluggish fermentations are often linked to a high sugar concentration in the grape juice, a lack of amino acids and vitamins, yeastinhibiting substances such as mycotoxins or killer factors of other yeasts, too high or too low fermentation temperatures, low suspended solids in the grape juice, as well as mistakes during the preparation of the yeast inoculum, such as a lack of oxygen supply (Bisson, 1999; Malherbe et al., 2007). Other studies have suggested that a low glucose-to-fructose ratio can lead to fermentation arrest, since most Saccharomyces yeast strains are glucophilic and high fructose levels tend to decrease general fermentation performance. This factor can usually be neutralised by adjusting the glucose-to-fructose ratio (Schütz \& Gafner, 1993, 1996).

\section{Short- and medium-chain fatty acids}

In addition to elevated ethanol levels, increasing concentrations of short- and medium-chain fatty acids and their esters may also inhibit the activity of yeast (LafonLafourcade et al., 1984; Guilloux-Benatier et al., 1998; Viegas et al., 1989) and other microorganisms (Hou, 2008; Bajpai et al., 2009; Karlova et al., 2010; Desbois, 2012; Calvo-Garrido et al., 2014), although all these toxic compounds arise predominately from a normal yeast metabolism (Viegas et al., 1989). Especially hexanoic, octanoic and decanoic acids were reported to be most prone to cause sluggish fermentation (Lafon-Lafourcade et al., 1984; Viegas et al., 1989). Being intermediate products derived from the synthesis of long-chain fatty acids by the yeast, their formation is strongly dependent on the yeast strain, grape juice composition and fermentation conditions such as temperature, $\mathrm{pH}$ and oxygen supply. Oxygen acts as an antagonist for the formation of short- and medium-chain fatty acids, thus they are released more abundantly under

*Corresponding author: E-mail address: sommers@appstate.edu

Acknowledgements: This research project was supported by the German Ministry of Economics and Technology (via AiF) and the FEI (Forschungskreis der Ernährungsindustrie e.V., Bonn). Project AiF 15833 N 
anaerobic conditions and oxygen depression (Malherbe et al., 2007).

According to Viegas et al. (1989), the inhibiting effect of fatty acids is based on the fact that yeast cell membranes are impermeable for charged dissociated weak acids, while the corresponding undissociated form is able to pass through the membrane due to a lack of charge. Once inside the yeast cell, the high $\mathrm{pH}$ will readily induce dissociation, triggering a severe drop in the cellular $\mathrm{pH}$. As a consequence, glycolysisrelated enzymes and ATPase will be inhibited and the fermentation rate will slow down or even stop (Viegas et al., 1989). As acid dissociation increases with rising $\mathrm{pH}$, the toxicity of fatty acids decreases with ascending $\mathrm{pH}$. In view of the $\mathrm{pK}$ values of the short-chain fatty acids, which range from 4.87 for hexanoic acid to 4.90 for decanoic acid, the majority of these fatty acids are undissociated and thus toxic at the typical wine $\mathrm{pH}$ of between 3.0 and 4.0. However, at low ethanol concentrations and low $\mathrm{pH}$, fatty acids are not soluble anymore and therefore lose their toxicity for the yeast, although other microorganisms can still be inhibited (Calvo-Garrido et al., 2014).

\section{Mineral compounds}

In the event of sluggish fermentation, the slowdown of fermentation during the stationary phase is induced only partly by nutrient depletion and rising ethanol levels. According to Dombek and Ingram (1986), magnesium deficiency plays an important role to slow down yeast metabolism. Yeast cells accumulate magnesium from the fermentation medium, making it the most abundant cation inside the cell. As a co-factor, magnesium is involved in the cell cycle, cell division, as well as in metabolic activities such as glycolysis and alcoholic fermentation (Dombek \& Ingram, 1986).

In high concentrations, most metals exhibit toxic effects on living organisms due to the inhibition of enzymatic systems. As a consequence, upper legal limits are defined in some countries, for example for calcium in Austria or sodium in Germany (for example German Wine Regulation i.d.F. der Bek. 01.09.1993, modified by MarkenrechtsreformG 25.10.1994, BGB1. I, 3082, 3115). Small amounts of heavy metals may be taken up by vines through their root system or by direct contact with fungicides containing metal atoms (Zoecklein et al., 1999). Yeast cells incorporate heavy metals during fermentation, which may deplete their original amount by up to $50 \%$ at the end of fermentation. Copper and iron are highly toxic for wine yeast at concentrations exceeding $100 \mu \mathrm{M}$ (about $6 \mathrm{mg} / \mathrm{L}$ in average) (Walker, 2000). However, when present at low concentrations, they will function as essential co-factors in cell metabolism, such as in respiration (Zoecklein et al., 1999). Wine treatments and fining agents like bentonite can also influence mineral composition (Nicolini et al., 2004), and therefore yeast activity.

\section{Grape variety and vineyard}

Some fermentation problems seem to be related to the grape variety itself. Chardonnay in particular has a tendency for sluggish fermentations (Ingledew \& Kunkee, 1985; Edwards et al., 1999; Nel et al., 2000), which may, among others, be linked to nutrient deficiencies. Independent of the sugar concentration, the minimum level of yeast assimilable nitrogen (YAN) should be above a threshold of $140 \mathrm{mg} / \mathrm{L}$ (Zoecklein et al., 1999). Some data suggest that several Chardonnay juices fell below this threshold (Ingledew \& Kunkee, 1985; Nel et al., 2000). Experiments conducted by Fornairon-Bonnefond et al. (2003) revealed that Chardonnay juices showed sluggish fermentations when any oxygen ingress was prevented. At the same time, juices with oxygen exposure $(37 \mathrm{mg} / \mathrm{L})$ showed faster fermentation and higher biomass formation (Fornairon-Bonnefond et al., 2003).

Some vineyards seem to be more susceptible to fermentation problems than others. Possible reasons could be a lack of nutrients in the soil, elevated levels of phytoalexins, or a larger diversity of natural microbial flora (Bisson, 1999). The total amount and composition of nitrogen compounds and micronutrients in the grape are influenced by a number of viticultural aspects as well. These include nitrogen supply of the vine by means of fertilisation, delivery of organic matter or irrigation, as well as rootstock selection. Increasing the nitrogen supply in the soil will lead to higher concentrations of nitrogen compounds in the berries, such as individual amino acids. Especially arginine and proline are strongly affected by excessive fertilisation at an early stage of growth (Malherbe et al., 2007). During ripening, the nitrogen level in the berry will rise, while the incidence of fungal rot and other spoilage organisms might deplete the nutrient status. The soundness of grape material is influenced by variety, rootstock, crop level, training system, spraying programme and climatic conditions (Kliewer, 1970).

The major objective of this research was to explain the occurrence of stuck fermentation in Chardonnay with deficiencies in mineral compounds, short- and medium-chain fatty acids, as well as amino acid supply. The comparison of fermentations conducted with juices from Pinot blanc versus Chardonnay allow us to elaborate on the inherent tendency of Chardonnay for sluggish fermentations.

\section{MATERIALS AND METHODS \\ Experimental wines}

Experiments in the course of this project were conducted exclusively in real must and wine. It is important to note that the fermentation trials presented here initially were designed for studying microbial interactions during wine fermentation, but provided deeper insight into sluggish and stuck fermentation than initially intended. Therefore the design includes variations in malolactic fermentation as well as spontaneous fermentation batches and the use of lysozyme. Trials were conducted in Chardonnay, Pinot blanc, Pinot noir and Pinot noir précoce (mutant grape variety of Pinot noir) in order to relate observations to specific varietal properties. Only certain microbial growth factors, like $\mathrm{pH}$ and sugar level, were altered to examine their effect on fermentation performance. All fermentations were conducted at small scale in $25 \mathrm{~L}$ glass carboys at a pilot winery. Fermentation temperature was constant at $18{ }^{\circ} \mathrm{C}$, and all experiments were done in duplicate. As standard yeast, a Saccharomyces cerevisiae was used (CY 3079, Lalvin, Lallemand, Montréal, Canada) at $20 \mathrm{~g} / 100 \mathrm{~L}$. Where applicable, malolactic fermentation (MLF) was induced by freeze-dried 
Oenococcus oeni (Enoferm ${ }^{\circledR}$ ALPHA, Lallemand; AWRI culture collection B421). Both microorganisms were used according to the manufacturer's instructions. MLF was either induced by inoculation or happened spontaneously with native bacteria. Some experiments were even conducted with native yeast for alcoholic fermentation $(\mathrm{AF})$ and native bacteria for MLF. The goal was to see the effect of microbial interaction on the general fermentation performance.

Chardonnay, Pinot blanc and Pinot noir trials were conducted in two vintages (2008 and 2009), while Pinot noir précoce was only done in 2009 . The grapes all originated from the same area and were grown under the same controlled conditions. The Chardonnay and the Pinot blanc especially were treated exactly the same in the vineyard to minimise variation in the raw material. White grapes were crushed, pressed and cold settled overnight before fermentation was inoculated. Red grapes were destemmed and fermented on the skins until the end of metabolic activity (AF or MLF). The red wines then were pressed and racked after a short settling time. No sulphur dioxide was added to any of the juices or mashes prior to fermentation. The batches with lysozyme received $100 \mathrm{mg} / \mathrm{L}$ prior to yeast inoculation to inhibit bacterial growth and prevent malolactic fermentation.

Initial juice or mash analysis was done by FTMIR spectroscopy (FT 120 WineScan, FOSS, Hillerød, Denmark) prior to fermentation. Chardonnay grapes were harvested on 2008-09-24 at a sugar level of 209.1 g/L, titratable acidity of $8.3 \mathrm{~g} / \mathrm{L}$, a pH of 3.5, $\alpha$-amino nitrogen (NOPA) of $157 \mathrm{mg} / \mathrm{L}$ and ammonium of $94 \mathrm{mg} / \mathrm{L}$. In 2009 the Chardonnay grapes were picked on 1 October with a sugar concentration of $229.1 \mathrm{~g} / \mathrm{L}$, titratable acidity of $7.2 \mathrm{~g} / \mathrm{L}$, a pH of 3.5 , NOPA of $168 \mathrm{mg} / \mathrm{L}$ and ammonium of $38 \mathrm{mg} / \mathrm{L}$. The 2008 Pinot blanc grapes were harvested on 25 September at a sugar level of $200.2 \mathrm{~g} / \mathrm{L}$, titratable acidity of $7.0 \mathrm{~g} / \mathrm{L}$, a pH of 3.4 , NOPA of $210 \mathrm{mg} / \mathrm{L}$ and ammonium of $108 \mathrm{mg} / \mathrm{L}$. In 2009, Pinot blanc grapes were picked on 23 September at a sugar concentration of $203.4 \mathrm{~g} / \mathrm{L}$, titratable acidity of $6.5 \mathrm{~g} / \mathrm{L}$, a pH of 3.6, NOPA of $227 \mathrm{mg} / \mathrm{L}$ and ammonium of $62 \mathrm{mg} / \mathrm{L}$. In 2008 the Pinot noir was harvested on 14 October at a sugar level of $206.8 \mathrm{~g} / \mathrm{L}$, titratable acidity of $12.3 \mathrm{~g} / \mathrm{L}$, a $\mathrm{pH}$ of 3.4 , NOPA of $264 \mathrm{mg} / \mathrm{L}$ and ammonium of $122 \mathrm{mg} / \mathrm{L}$. The 2009 Pinot noir was picked on 5 October at a sugar level of $235.2 \mathrm{~g} / \mathrm{L}$, titratable acidity of $8.5 \mathrm{~g} / \mathrm{L}$, a pH of 3.2 , NOPA of $274 \mathrm{mg} / \mathrm{L}$ and ammonium of $43 \mathrm{mg} / \mathrm{L}$. Pinot noir précoce, which was only included in 2009, was harvested on 14 September at a sugar concentration of $224.5 \mathrm{~g} / \mathrm{L}$, titratable acidity of $5.6 \mathrm{~g} / \mathrm{L}$, a $\mathrm{pH}$ of 3.5 , NOPA of $248 \mathrm{mg} / \mathrm{L}$ and ammonium of $67 \mathrm{mg} / \mathrm{L}$.

Fermentation performance and yeast-related parameters like fermentable sugar, total acid, ethanol and aamino acids (NOPA) were monitored using FT-MIR. Samples for fermentation control were taken daily until fermentation arrest could be observed. After that, sampling was done only every third day. The finished wines were filtered and bottled prior to final analysis.

Statistical data analysis by means of principal component analysis, analysis of variance and co-variance, and discriminant analysis, was done with the Ecxel Statistics Add-on XL-Stat 2010 (Addinsoft Deutschland, Andernach, Germany).

\section{Mineral analysis by atomic absorption spectroscopy (AAS)}

The analysis of selected cations for the characterisation of environmental conditions was performed by AAS. Since only finished wines were analysed, most of the samples contained virtually no sugar. All wines thus could be analysed without pre-dilution, except for samples destined for the analysis of magnesium, which was present in too high concentrations. Preliminary tests revealed that sample preparation like microwave extraction did not lead to significant improvements in the results. The flame AAS instrument used was an AAnalyst 700 (Perkin Elmer, Rodgau, Germany) with acetylene as combustible gas $(2.0 \mathrm{~L} / \mathrm{min})$ and air as an oxydans $(17 \mathrm{~L} / \mathrm{min})$. Instrument control and data acquisition were performed with the software Winlab 32 for AA (Perkin Elmer, Rodgau, Germany). For magnesium, the wavelength was set to $285.2 \mathrm{~nm}$ with a slit-width of $0.7 \mathrm{H}$ and samples were analysed at a dilution of 1:97. Iron was analysed at $248.3 \mathrm{~nm}$ undiluted with a slit-width of $0.2 \mathrm{H}$. For zinc, a wavelength of $213.9 \mathrm{~nm}$ was chosen and undiluted samples were analysed with a slit-width of $0.7 \mathrm{H}$. The copper content of the undiluted samples was analysed at $324.8 \mathrm{~nm}$ and a slitwidth of $0.7 \mathrm{H}$. Finally, manganese was analysed undiluted at $279.5 \mathrm{~nm}$ and a slit-width of $0.2 \mathrm{H}$.

\section{Amino acid analysis by GC-MS}

Sample preparation was conducted with the commercial kit "EZ:faast For Free (Physiological) Amino Acid Analysis by GC-MS" (Phenomenex, Aschaffenburg, Germany). The protocol includes solid phase extraction (SPE) on a cation exchanger (SCX; benzene-sulphonic acid based on silica gel) to separate the amino acids from the matrix, and derivatisation with propyl-chloroformiate followed by GCMS analysis. Norvaline $(200 \mu \mathrm{M})$ was used as an internal standard for quantification.

The GC instrument used was a FISONS Instruments (today ThermoFisher Scientific, Dreieich, Germany) GC 8000 TOP series 8060 , equipped with a split/splitless injector connected to a MD 800 quadrupole MS (FISONS). Samples $(2 \mu \mathrm{L})$ were injected in split mode (1:5) using an AS 800 autosampler (FISONS), with an injector temperature of $230{ }^{\circ} \mathrm{C}$. A $10 \mathrm{~m}$ $\times 0.25 \mathrm{~mm}$ i.d. fused silica capillary, coated with $0.2 \mu \mathrm{m}$ of an unknown stationary phase (ZB-AAA, Phenomenex, Aschaffenburg, Germany), was used as a separation column. Helium was used as carrier gas with a constant inlet pressure of $75 \mathrm{kPa}$. The oven temperature was initially held at $110^{\circ} \mathrm{C}$ for $1 \mathrm{~min}$ and then raised to $320^{\circ} \mathrm{C}$ at a rate of $20^{\circ} \mathrm{C} / \mathrm{min}$, finally held for $2 \mathrm{~min}$. The MS transfer line and ion source temperature were held at $250{ }^{\circ} \mathrm{C}$ and $240{ }^{\circ} \mathrm{C}$ respectively. Electronic ionisation was realised at $70 \mathrm{eV}$. Detection (EI+) was in the full-scan mode $(m / z 60-300)$ with four scans per second, and quantification was done on extracted ion traces of fragment ions normalised to norvaline as an internal standard. Quantifier and qualifier ions were used as specified by the manufacturer of the kit (Phenomenex, Aschaffenburg, Germany). Instrument control and data acquisition were performed with Xcalibur (Version 1.2; ThermoFisher Scientific, Dreieich, Germany).

Arginine cannot be derivatised because of the internal 
structure of the molecule, so it had to be transformed enzymatically into ornithine by arginase. The enzyme activity was set to $8300 \mathrm{U} / \mathrm{mL}(1 \mathrm{U} \approx 1 \mu \mathrm{mol} / \mathrm{min}) .10 \mu \mathrm{L}$ of arginase solution were added to $5 \mathrm{~mL}$ of sample and incubated for $1 \mathrm{~min}$ prior to further processing.

\section{Free fatty acids}

The method used for analysing short- and medium-sized fatty acids was based on a GCMS method designed for the characterisation of volatile phenols. Samples were prepared by solid phase extraction (Lichrolut EN $200 \mathrm{mg}$, Merck KGaA Darmstadt, Germany) and GC-MS analysis of the dichloromethane extract.

The GC instrument used was a Thermo Trace GCxGC (Thermo Fisher Scientific, Dreieich, Germany), equipped with a split/splitless injector connected to a Finnigan Trace DSQ (Thermo Fisher Scientific, Dreieich, Germany). Samples $(2 \mu \mathrm{L})$ were injected in splitless mode with a surge pressure of $150 \mathrm{kPa}$ for 2 min using a TriPlus AS autosampler (Thermo Fisher Scientific, Dreieich, Germany), with an injector temperature of $230{ }^{\circ} \mathrm{C}$. A $20 \mathrm{~m} \times 0.18 \mathrm{~mm}$ i.d. fused silica capillary column, coated with $0.32 \mu \mathrm{m}$ of a $5 \%$ phenyl $95 \%$ dimethylpolysiloxane stationary phase (ZB-5, Phenomenex, Aschaffenburg, Germany), was used as a separation column. Helium was used as carrier gas with a constant inlet pressure of $102 \mathrm{kPa}$. The oven temperature was initially held at $40{ }^{\circ} \mathrm{C}$ for $4 \mathrm{~min}$ and then raised to $180{ }^{\circ} \mathrm{C}$ at a rate of $3{ }^{\circ} \mathrm{C} / \mathrm{min}$, held for $0.5 \mathrm{~min}$ and raised to $300{ }^{\circ} \mathrm{C}$ at a rate of $6^{\circ} \mathrm{C} / \mathrm{min}$. The final temperature was held for another $5 \mathrm{~min}$. The MS transfer line and ion source temperature were held at $250{ }^{\circ} \mathrm{C}$. Electronic ionisation was realised at $70 \mathrm{eV}$. Detection $(\mathrm{EI}+)$ was in the full-scan mode $(\mathrm{m} / \mathrm{z} 29$ to 161) and quantification was done on extracted ion traces of fragment ions. Instrument control and data acquisition were performed with Xcalibur (Version 1.2, ThermoFisher Scientific, Dreieich, Germany).

\section{RESULTS}

\section{Fermentation performance}

All analytical data from the Chardonnay wines of 2008 and 2009 were compared to Pinot blanc trials in which no fermentation problems could be observed. Oenological factors like yeast strain, fermentation temperature, aeration, degree of must clarification and fermentation regime were similar, which makes it possible to relate all phenomena directly to variety-specific properties. The red wine fermentations only serve as a reference point for analytical parameters and are not discussed in further detail concerning their general fermentation performance, since no problems could be observed. The results show fermentation arrests in the Chardonnay trials, while fermentations of all other grape varieties finished to dryness. In fact, almost every trial made with Chardonnay showed sluggish or stuck fermentation (Fig. 1), while all Pinot blanc, Pinot noir and Pinot noir précoce wines completed fermentation with virtually no residual sugar within ten days (data not shown). The observation that almost none of the Chardonnay wines finished fermentation independently of the fermentation strategy implies that there must be a number of related factors that could cause fermentation arrest, independent of yeast and bacteria selection and the resulting fermentation strategy. Almost all Chardonnay wines had a residual sugar of more than $10 \mathrm{~g} / \mathrm{L}$ after at least 40 days of fermentation. In 2009, two wines would have been marketable as dry, since they would have met the legal requirements. However, complete metabolism of the sugar could not be achieved in any of the wines, which would be the goal of modern commercial winemaking. The fermenting yeast populations were not monitored during fermentation because the metabolic rate shown in Fig. 1 did not suggest major differences among the trials, except for the spontaneous fermentation, which could be expected. With no major variation in yeast population performance, the reasons for fermentation problems more likely are related to the composition of the media. General juice analysis performed by FT-MIR revealed minor differences between 2008 and 2009, with the latter vintage having slightly higher fermentable sugar. However, since this could be observed in all grape varieties, a correlation with fermentation problems is unlikely.
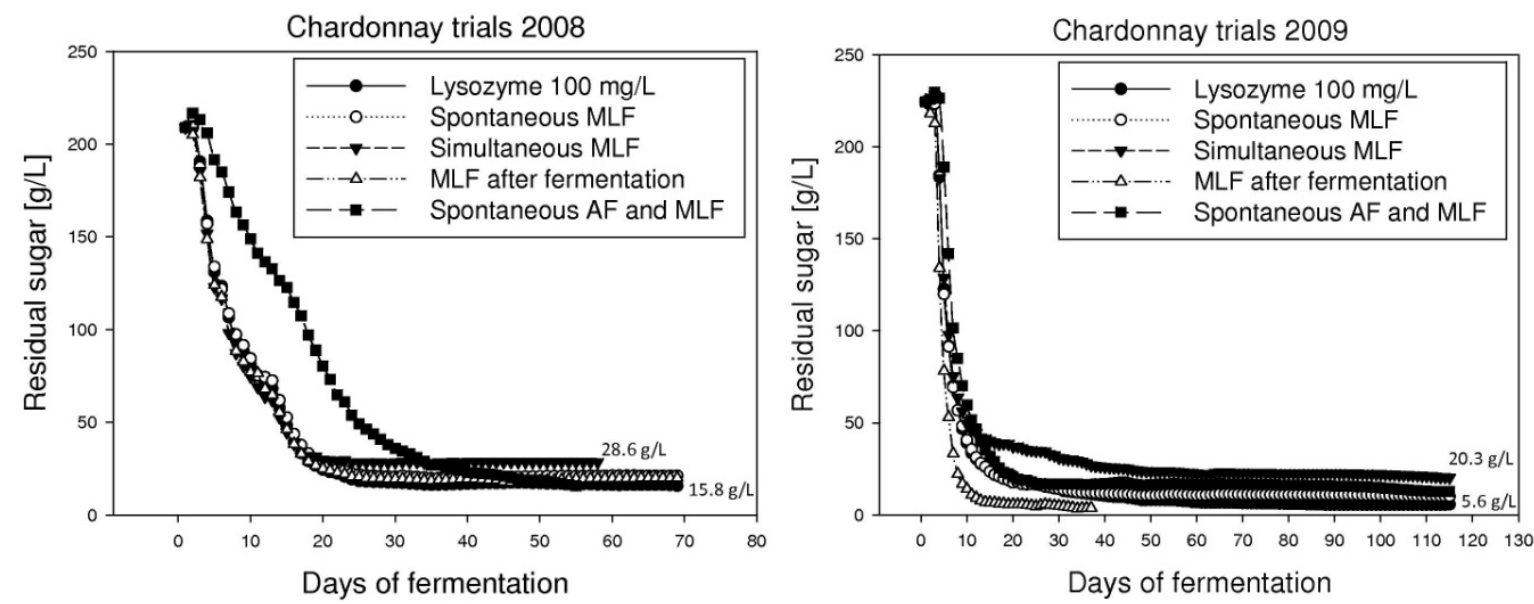

FIGURE 1

Fermentation performance of Chardonnay trials in 2008 and 2009 (AF: alcoholic fermentation, MLF: malolactic fermentation). The final residual sugar is shown for minimum and maximum values (MLF: malolactic fermentation, AF: alcoholic fermentation) 


\section{Amino acid supply}

The most frequently occurring reason for sluggish fermentation is a lack of nutrients, especially nitrogen depression (Zoecklein et al., 1999). The total amount of amino acids in grape juice can be altered by extended skin contact and the addition of yeast hulls or other products based on autolysed yeast cells. The composition is also influenced by the grape variety. The analysis of the amino acid composition of Chardonnay must revealed specific properties that are significantly different from other varieties (Table 1).

\section{Fatty acid profile}

The comparison of the fatty acid profiles of Chardonnay and Pinot blanc, shown in Fig. 2, reveals major differences during alcoholic and malolactic fermentation. Chardonnay tends to have higher amounts of hexanoic and octanoic acid compared to Pinot blanc.

\section{Composition of minerals}

Another parameter that is known to influence fermentation performance in general is the mineral composition of the medium. When it comes to growth and fermentation, Saccharomyces cerevisiae shows a certain affinity towards metal cations: $\mathrm{Mg}^{2+}>\mathrm{Cu}^{2+}>\mathrm{Zn}^{2+}>\mathrm{Mn}^{2+}>\mathrm{Ni}^{2+}>\mathrm{Ca}^{2+}>\mathrm{Sr}^{2+}$.

TABLE 1

Amino acid composition in Chardonnay juice compared to Pinot blanc, vintage 2008.

\begin{tabular}{lllll}
\hline & \multicolumn{2}{c}{ Chardonnay } & \multicolumn{2}{c}{ Pinot blanc } \\
\cline { 2 - 5 } & {$[\mathrm{mg} / \mathrm{L}]$} & {$[\%]$} & {$[\mathrm{mg} / \mathrm{L}]$} & 198.8 \\
\hline Alanine & 283.5 & 19.5 & 4.9 & 17.9 \\
Glycine & 5.3 & 0.4 & 21.5 & 0.4 \\
Phenylalanine & 17.4 & 1.2 & 31.5 & 1.9 \\
Leucine & 15.8 & 1.1 & 17.3 & 2.8 \\
Isoleucine & 8.1 & 0.6 & 278.4 & 1.6 \\
Proline & 756.6 & 52.1 & 20.1 & 25.0 \\
Tryptophane & 19.9 & 1.4 & 3.4 & 1.8 \\
Methionine & 4.3 & 0.3 & 232.1 & 0.3 \\
Glutamate & 148.0 & 10.2 & 27.7 & 20.8 \\
Valine & 19.2 & 1.3 & $<1.0$ & 2.5 \\
Cysteine & 7.0 & 0.5 & 9.1 & 0.0 \\
Ornithine & 9.9 & 0.7 & 3.4 & 0.8 \\
Lysine & 7.5 & 0.5 & 26.6 & 0.3 \\
Histidine & 21.6 & 1.5 & 15.8 & 2.4 \\
Tyrosine & 20.2 & 1.4 & 198.4 & 1.4 \\
Aspartate & 104.9 & 7.2 & 24.7 & 17.8 \\
Arginine & 4.5 & 0.3 & & 2.2
\end{tabular}

TABLE 2

Minimum, maximum and average mineral levels for each variety over the vintages 2008 and 2009 analysed by AAS.

\begin{tabular}{|c|c|c|c|c|c|c|}
\hline & & Iron & Copper & Zinc & Manganese & Magnesium \\
\hline & & \multicolumn{5}{|c|}{$[\mathrm{mg} / \mathrm{L}]$} \\
\hline \multirow[t]{3}{*}{ Chardonnay } & $\min$ & 0.14 & 0.01 & 0.97 & 0.41 & 43.76 \\
\hline & $\max$ & 1.03 & 1.05 & 2.61 & 0.78 & 110.67 \\
\hline & average & 0.58 & 0.25 & 1.54 & 0.64 & 76.91 \\
\hline \multirow[t]{3}{*}{ Pinot blanc } & $\min$ & 0.11 & 0.00 & 0.73 & 0.43 & 51.41 \\
\hline & $\max$ & 1.10 & 0.34 & 1.85 & 1.14 & 223.97 \\
\hline & average & 0.56 & 0.14 & 1.23 & 0.78 & 133.31 \\
\hline \multirow[t]{3}{*}{ Pinot noir } & $\min$ & 2.05 & 0.00 & 0.65 & 1.03 & 55.73 \\
\hline & $\max$ & 4.66 & 0.18 & 2.78 & 1.90 & 141.26 \\
\hline & average & 3.06 & 0.03 & 2.03 & 1.37 & 100.51 \\
\hline \multirow[t]{3}{*}{ Pinot noir précoce } & $\min$ & 0.60 & 0.03 & 1.03 & 1.16 & 84.34 \\
\hline & $\max$ & 2.85 & 0.51 & 1.90 & 1.51 & 111.21 \\
\hline & average & 1.56 & 0.13 & 1.32 & 1.27 & 99.14 \\
\hline
\end{tabular}


In order to prevent toxic levels of each mineral, their uptake is regulated by specific transport mechanisms (Walker, 2000). Table 2 shows the minimum, maximum and average mineral levels for each variety over two vintages, displaying obvious differences among the different varieties. In addition, Fig. 3 shows the results of a discriminant analysis of selected minerals including all experimental wines from the vintage 2009 to make the differences between the varieties clearer and statistically relevant.

\section{DISCUSSION}

It is very interesting to note that previous studies also reported fermentation problems with Chardonnay, although it seems as if it could not be related specifically to the properties of certain varieties (Ingledew \& Kunkee, 1985; Rasmussen et al., 1995; Edwards et al., 1999; Nel et al., 2000; FornaironBonnefond et al., 2003). To the best of our knowledge, this is the first study that relates differences between grape varieties to the occurrence of fermentation problems.

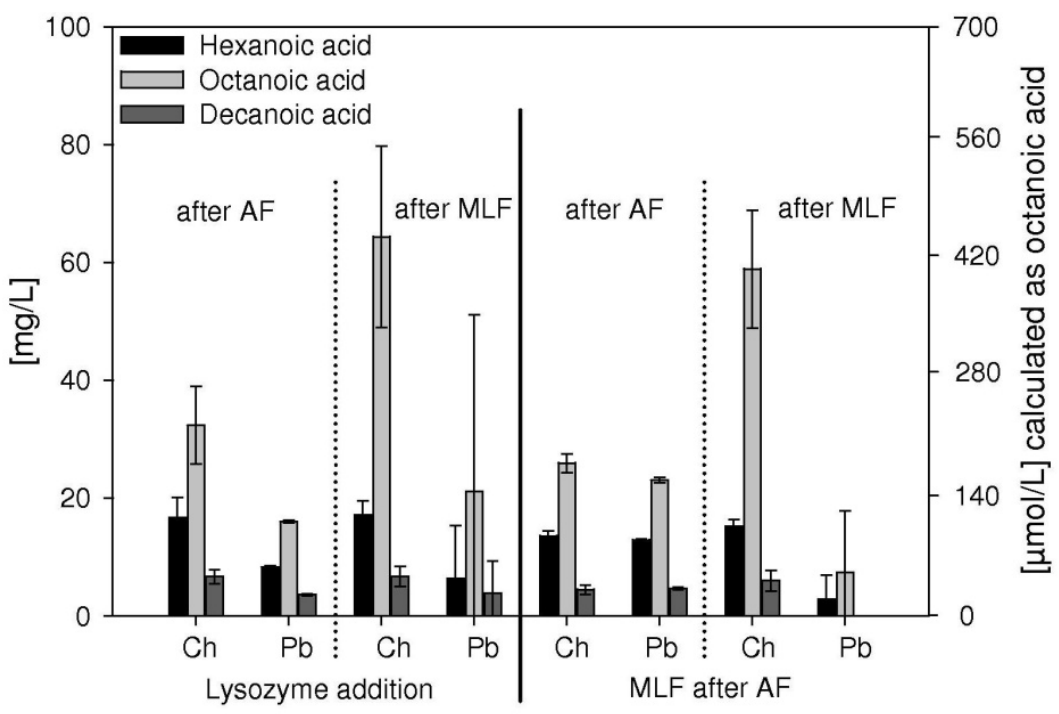

FIGURE 2

Comparison of selected fatty acids between Chardonnay $(\mathrm{Ch})$ and Pinot blanc $(\mathrm{Pb})$ trials (vintage 2008) in the course of vinification at two different points in time (AF: alcoholic fermentation, MLF: malolactic fermentation). The experiments, first with added Lysozyme, and second with inoculated MLF after fermentation, serve as examples. Error bars represent experimental duplicates.

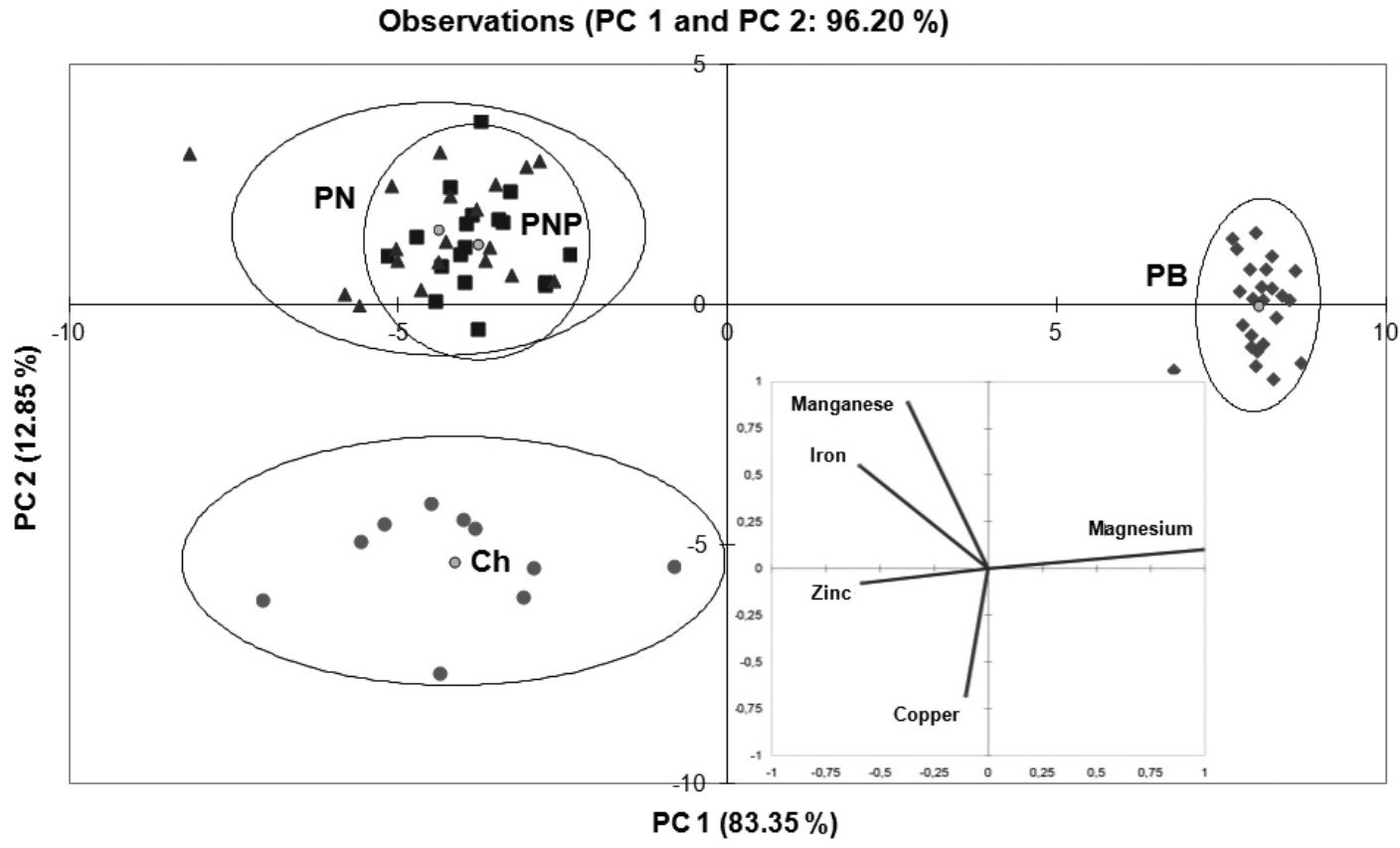

FIGURE 3

Discriminant analysis of all experimental wines 2009 regarding their mineral composition (Ch: Chardonnay, Pb: Pinot blanc, Pn: Pinot noir, Pnp: Pinot noir précoce), confidence interval 95\%, centroids shown. The loadings plot (bottom right quadrant) characterises the groups according to their mineral composition. 


\section{Influence of amino acid composition}

Looking at the amino acid composition of Chardonnay, the large proportion of proline is especially interesting. Since this amino acid cannot be utilised by yeast under normal vinification conditions (Boulton et al., 1996), a large amount could pose problems because it reduces the assimilable nitrogen for the yeast. Chardonnay is one of the grape varieties that accumulates proline during growing and véraison. In contrast, there are a number of grape varieties that accumulate arginine instead, for example Pinot noir and Cabernet Sauvignon (Bell \& Henschke, 2005). Consequently, in the course of the ripening process, the proportion of proline in the juice increases significantly in Chardonnay (Zoecklein et al., 1999), which reduces the yeast's useable nitrogen. This phenomenon can also be observed in several fruit varieties, for example oranges (Schobinger, 2001).

If proline is not considered, the amino acid composition in Chardonnay is comparable to other grape varieties. Most of the compounds are present in amounts below $2 \%$. These results correspond to those in previous publications (Fantozzi \& Montedoro 1974), whereas the exact composition varies between grape varieties, but also between vintages and sites (Ribéreau-Gayon et al., 2000).

In contrast to the Chardonnay trials, all other studied varieties (Pinot blanc, Pinot noir and Pinot noir précoce) showed no sluggish or arrested fermentation. The main difference in the amino acid composition is the amount of proline, which is significantly lower in all Pinot varieties compared to Chardonnay. Usually, between 60 and $90 \%$ of total nitrogen is present as amino acids (Würdig \& Woller, 1989), equally situated in the pulp and skin of the berry (Würdig \& Woller, 1989; Boulton et al. 1996). Since the extraction method for the experimental wines was similar, there was no major influence on the amino acid composition. Most of the variance therefore is related to variety.

The vintage variation in the amino acid composition between 2008 and 2009 is fairly low. Grape varieties can be characterised by certain amino acids. In relation to Pinot noir the two white grape varieties show lower total levels of amino acids and a lower level of yeast-assimilable nitrogen (YAN). Bell and Henschke (2005) suggest that a high ratio between proline and arginine lowers the YAN and limits the available nutrients for the yeast, being a potential source of fermentation problems.

Compared to the Chardonnay must, it is obvious that the Pinot blanc juice contained approximately only $25 \%$ of proline, independent of the degree of grape rot, which leaves more yeast available amino acids prior to fermentation. Pinot noir must contained only $15 \%$ proline (data not shown) at a similar level of total nitrogen. Since sluggish fermentation with Pinot noir and even Blanc de noir and Pinot blanc is reported in the literature less frequently, the amino acid composition is likely to influence the overall fermentation performance of the grape variety. It remains unclear if a high amount or elevated proportion of proline is able to inhibit yeast metabolism or amino acid uptake under fermentation conditions by obstructing amino acid transporters, although it appears to be possible.

The concentrations of the two amino acids that are only partly yeast assimilable, threonine and proline, increase during véraison (Malherbe et al., 2007), which partially explains why overripe grape musts tend to ferment slower. The uptake and use of amino acids generally follow a certain pattern during alcoholic fermentation (Walker, 2000). Most of the amino acids are consumed within the first days of fermentation to produce biomass and enzymes. After the initial uptake, amino acids are slowly released from the cells by passive diffusion (Hervé \& Guilloux-Benatier, 2006). The reason why proline and threonine cannot be used by the yeast population is that transporters are inhibited by high ethanol levels (Zoecklein et al., 1999). A direct autolysis only occurs after approximately six months (Hervé \& GuillouxBenatier, 2006), and every amino acid release prior to this point is due to cell leakage. Although the concentration of proline in this study was not extremely high compared to other amounts reported previously (Bell \& Henschke, 2005), the deficiency in YAN compared to Pinot blanc is obvious in the Chardonnay juice.

The course of $\alpha$-amino acid metabolism in these experiments follows a similar pattern, shown in Fig. 4, except for the trial using both spontaneous alcoholic fermentation and spontaneous malolactic fermentation. The decrease in amino acid concentration during vinification is visible to a lesser extent. One possible explanation could be the great variety of micro-organisms, which have different ethanol-tolerance levels and release amino acids as soon as they arrest metabolism. While some species consume nitrogen compounds from the medium, others stop growing and release amino acids. This complex interaction has been described for lactic acid bacteria before (Aredes Fernandez \& Manca Nadra, 2006), but could also be applicable to more diverse interactions between different yeast species.

Despite the differences in amino acid uptake, fermentation problems occurred in all the batches. In fact, insufficient nitrogen supply is not likely to be the only explanation for sluggish yeast metabolism, therefore other factors were evaluated that have been described in the literature before (reviewed by Bisson (1999) and Malherbe et al. (2007)).

\section{Influence of toxic fatty acids}

The toxicity of fatty acids described in the literature increases with increasing chain length of the molecule (Viegas et al., 1989). Decanoic acid induces cell death at a concentration as low as $46 \mu \mathrm{M}(7.9 \mathrm{mg} / \mathrm{L})$. Lower levels increase the permeability of the membrane and weaken the stress resistance of the yeast cell (Alexandre \& Charpentier, 1998). In the experimental wines, major differences can be observed in the levels of hexanoic and decanoic acid, which may have a lower toxicity but are present in two-fold concentrations in Chardonnay at some stages of the fermentation.

Short- and medium-chain fatty acids inhibit the glucose transporter system in yeast, especially transporters with higher affinity. They are responsible for glucose uptake in the later stages of fermentation at sugar levels around $10 \mathrm{~g} / \mathrm{L}$ (Alexandre \& Charpentier, 1998). The main reason for the great number of different transporter systems is the variety of different environmental conditions during fermentation, ranging from very high to very low sugar concentrations (Bisson, 1999). Since the experimental wines that showed 


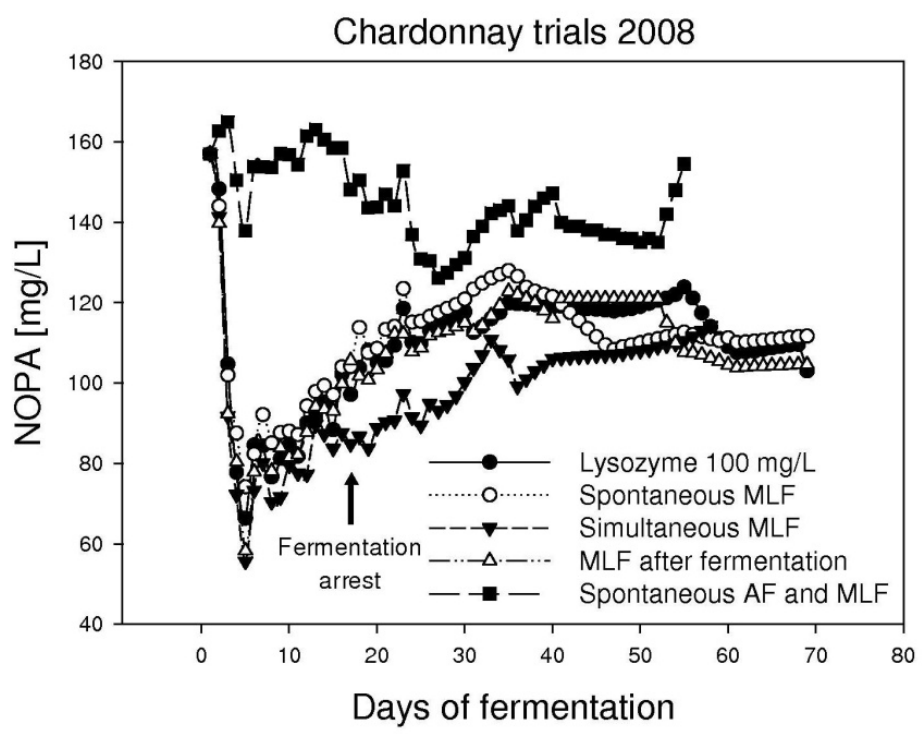

FIGURE 4

Course of aamino acids (NOPA) during Chardonnay vinification (AF: alcoholic fermentation, MLF: malolactic fermentation)

sluggish and stuck fermentations had a slower fermentation rate, below $20 \mathrm{~g} / \mathrm{L}$ residual sugar, it implies a correlation between the elevated fatty acid level and the fermentation problems.

Excessive must clarification can lead to high concentrations of fatty acids. According to the literature, this is probably due to the depletion of long-chain fatty acids derived from the grape. Consequently, the yeast starts to produce long-chain fatty acids to secure its supply. As soon as oxygen becomes the limiting factor, the synthesis arrests and leaves intermediate products behind. These shortand medium-chain fatty acids then accumulate in the cell, resulting in the inhibition of glycolytic enzymes (Alexandre $\&$ Charpentier, 1998), which directly affect the fermentation rate. In the present wines, the concentration of volatile acidity, the shortest fatty acid, was also higher in Chardonnay than in Pinot blanc in both vintages $(0.7$ to $1.0 \mathrm{~g} / \mathrm{L}$ in Chardonnay vs 0.5 to $0.6 \mathrm{~g} / \mathrm{L}$ in Pinot blanc), which supports the correlation described by Alexandre and Charpentier (1998). All white musts were settled for clarification without filtration, resulting in a similar turbidity prior to fermentation.

Based on the analytical data of all wines from both vintages, it is possible to create a model that displays the major differences in the fatty acid profile. Fig. 5 shows that Pinot blanc tends to contain higher levels of hexanoic acid, while Chardonnay shows larger amounts of octanoic and decanoic acid. Since hexanoic acid is less toxic than the other two, it becomes obvious that the Pinot blanc wines provided better fermentation conditions compared to Chardonnay. A similar study is also documented in the literature, where Chardonnay was also shown to contain high levels of short- and medium-chain fatty acids (Ramey et al., 1986). However, to the best of our knowledge, a direct comparison with other varieties under standardised conditions has not been described so far.

\section{Influence of mineral supply}

The analysis of the mineral composition shows that Chardonnay can be characterised by higher levels of copper and lower magnesium concentrations. Since no copper was used during winemaking and the Chardonnay juice was not treated differently from the Pinot blanc, it very likely originates from the vineyards. While viticultural practices were again comparable to Pinot blanc, with the vineyards being very close to each other and both managed by the same viticulturist, Chardonnay seems to have a higher affinity for copper or a stronger uptake through the root system. Pinot blanc, on the other hand, contained more magnesium, which is described as supportive for the proliferation and fermentation performance of yeast (Dombek \& Ingram, 1986), whereas copper becomes toxic in high amounts (Walker, 2000). The part of vinification that is mainly affected by copper is yeast proliferation (Bisson, 1999). Magnesium, on the other hand, is involved in every phosphate-transferring enzymatic process, especially in ATP synthesis. Moreover, all reproductive processes of DNA and cell function, as well as protein biosynthesis, are magnesium dependent. Magnesium deficiency leads to an increased loss of potassium and an increased uptake of calcium and sodium into the cell. Consequently, the pool of minerals in the cell is modified and the ATP synthesis is disturbed (Schmidt \& Bayer, 1982). Magnesium cannot be replaced in reactions including phosphate (Kunze, 1998).

Copper and iron are important co-factors during respiration. Copper is essential in low concentrations but toxic in high amounts, since it disturbs the integrity of the plasma membrane. The physiological effect of iron in yeast cells remains mostly unclear (Walker, 2000). In both red wine varieties in this study, manganese and iron dominated the range of minerals. Manganese is important for growth and metabolism as a regulator for key enzymes. Unlike magnesium, manganese does not accumulate in the yeast cell, since the transport mechanism is inhibited by high magnesium concentrations (Walker, 2000). Fig. 3 shows this 

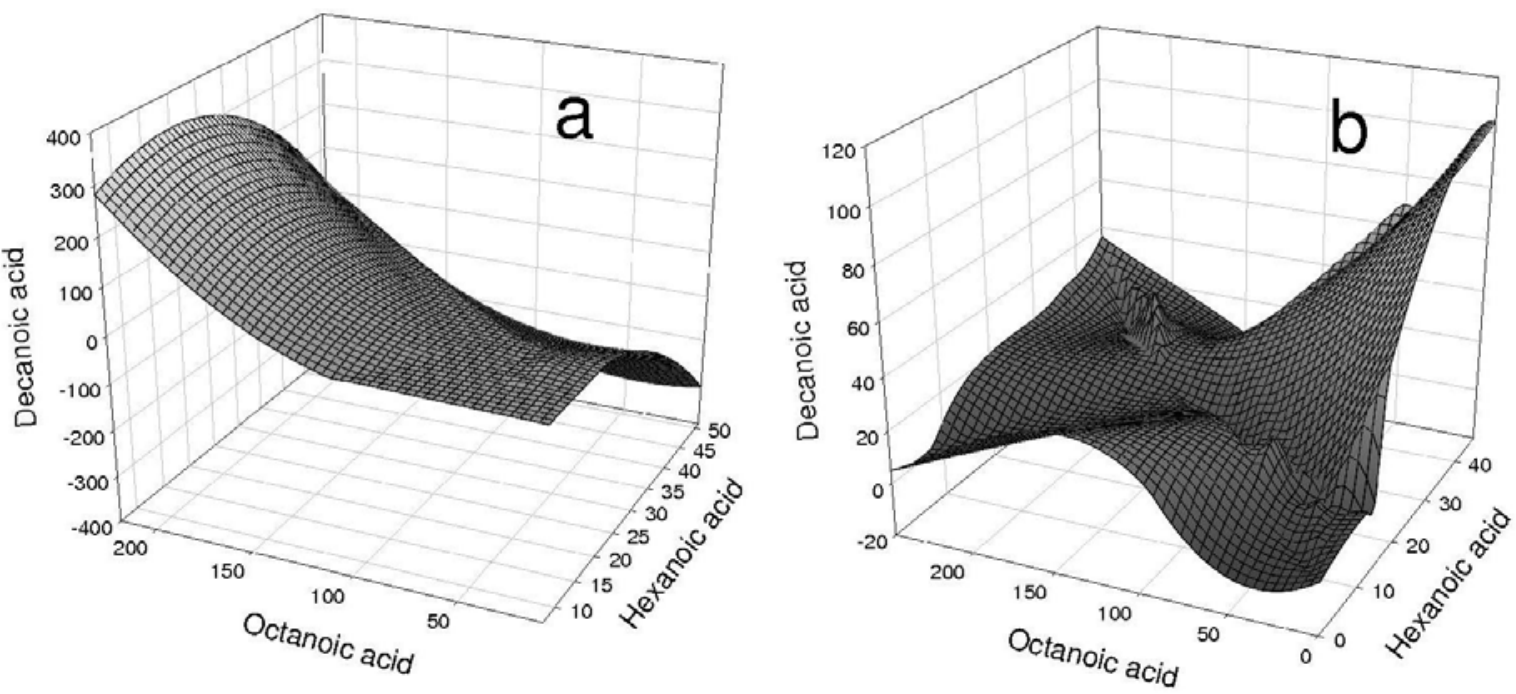

FIGURE 5

Comparison of the fatty acid profiles of Chardonnay [a] and Pinot blanc [b]. All values used for the model are in mg/L.

correlation because magnesium and manganese are situated at opposite sides of the plot.

Zinc is also needed for cell growth, since it influences protein synthesis and is used for enzymatic reactions during fermentation (Kunze, 1998). Zinc deficiency causes budding to cease and cell cycle arrest in the G1 phase (Walker, 2000). Although the Chardonnay wines may have enough zinc, they are characterised by a lack of magnesium, which cannot be balanced. It has been reported before that the addition of certain minerals can lead to an increased fermentation rate and even restart sluggish fermentations (Dombek \& Ingram, 1986; Nabais et al., 1988). Considering the elevated amount of copper in the medium, unpleasant environmental conditions are created for the yeast, which might have contributed to fermentation arrest.

It has previously been demonstrated that the mineral composition of the soil does not reflect in the range present in the grapes (Boulton et al., 1996; Kment et al., 2005). Since the grapes for these experiments were grown under the same conditions and most likely with a similar mineral composition in the soil, it cannot be clarified what caused the differences, especially in copper concentration, at that point.

\section{Statistical analysis of correlations}

A statistical evaluation of the influencing factors was done by analysis of covariance. Table 3 shows the corresponding levels of significance, implying that only three parameters have a significant influence on high residual sugar when the grape variety is not taken into account. It was described earlier that Chardonnay accumulates proline instead of arginine (Zoecklein et al., 1999; Bell \& Henschke, 2005), which reflects in the significance levels shown for Pinot blanc and Chardonnay.

High levels of hexanoic acid have a statistically significant influence on high residual sugar. Surprisingly, no other fatty acid could be shown to have a significant influence, but this might be due to the relatively low levels in wine. Since oxygen is the limiting factor during yeast growth, short-chain fatty acids occur much more frequently. As the synthesis of fatty acids proceeds, the longer chains would increase in concentration and probably reach the threshold of significance for causing high residual sugar.

A possible reason why minerals like manganese, zinc or copper cannot be found to have a significant influence could be the great dataset. There is a lot of variation depending on the fermentation regime, because yeasts and bacteria are all using minerals as co-factors during metabolism. Depending on the variety of organisms involved, the mineral composition is altered to a greater extent. However, a lack of manganese and magnesium or excess amounts of copper might have influenced the fermentation performance in this study. Previous studies provide partial solutions to the factors also discussed in this work, including fermentation on the skins, aeration, fining agents like bentonite and yeast hulls, as well as adjustments of the must composition prior to or in the early stages of fermentation (Ramey et al., 1986; Schütz \& Gafner, 1996; Nel et al., 2000; Fornairon-Bonnefond et al., 2003; Nicolini et al., 2004).

\section{CONCLUSIONS}

In conclusion, the contribution of an unbalanced amino acid composition, elevated levels of toxic fatty acids, and unfavourable mineral supply could have caused the sluggish fermentation and, in most cases, the metabolic arrest. Consequently, malolactic fermentation started prematurely in the presence of high sugar levels, which led to an increase in volatile acidity. As a result the wines were described as spoiled.

The support of yeast activity and metabolism has to be the first priority during vinification. The experiments have shown that this cannot be done only by monitoring the nutrient situation or oxygen supply. The reasons for sluggish and stuck fermentation can be much more complex than that, and might even be related to the grape variety. Synergy effects between several factors described in this work furthermore contribute to the complexity of the problem. 
TABLE 3

Levels of significance in the co-variance analysis explaining high residual sugar.

\begin{tabular}{|c|c|c|c|c|}
\hline & Correlation & Coefficient of determination & $\operatorname{Pr}>|t|$ & Significance \\
\hline Iron & -0.034 & 0.001 & 0.850 & n.s. \\
\hline Copper & 0.034 & 0.001 & 0.785 & n.s. \\
\hline Zinc & 0.306 & 0.094 & 0.890 & n.s. \\
\hline Manganese & -0.470 & 0.221 & 0.790 & n.s. \\
\hline Magnesium & 0.227 & 0.052 & 0.891 & n.s. \\
\hline Hexanoic acid & 0.524 & 0.275 & 0.399 & $* *$ \\
\hline Octanoic acid & -0.105 & 0.011 & 0.975 & n.s. \\
\hline Decanoic acid & -0.033 & 0.001 & 0.891 & n.s. \\
\hline Proline & 0.928 & 0.861 & 0.544 & $* * *$ \\
\hline Arginine & -0.931 & 0.867 & 0.317 & $* * *$ \\
\hline
\end{tabular}

n.s.: not significant, ${ }^{*}: \alpha=0.05,{ }^{*}: \alpha=0.01,{ }^{* * *}: \alpha=0.001$. Bold font indicates a statistically significant influence of the parameter.

\section{LITERATURE CITED}

Alexandre, H. \& Charpentier, C., 1998. Biochemical aspects of stuck and sluggish fermentation in grape must. J. Ind. Microbiol. Biotechnol. 20, 20 27.

Aredes Fernandez, P.A. \& Manca Nadra, M.C., 2006. Growth response and modifications of organic nitrogen compounds in pure and mixed cultures of lactic acid bacteria from wine. Curr. Microbiol. 52, 86-91.

Bajpai, V.K., Kim, H.R., Hou, C.T. \& Kang, S.C., 2009. Bioconverted products of essential fatty acids as potential antimicrobial agents. New Biotechnology 26, 122-130. doi:10.1016/j.nbt.2009.07.007

Bell, S.J. \& Henschke, P.A., 2005. Implications of nitrogen nutrition for grapes, fermentation and wine. Aust. J. Grape Wine Res. 11, 242-295.

Bisson, L.F., 1999. Stuck and sluggish fermentations. Am. J. Enol. Vitic. $50,107-119$.

Boulton, R.B., Singleton, V.L., Bisson, L.F. \& Kunkee, R.E., 1996. Principles and practices of winemaking. Kluwer Academic/Plenum Publishers, New York.

Calvo-Garrido, C., Elmer, P.A.G., Parry, F.J.. Vinas, I., Usall, J., Torres, R., Agnew, R.H. \& Teixido, N., 2014. Mode of action of a fatty acid-based natural product to control Botrytis cinerea in grapes. J. Appl. Microbiol. 116, 967-979. doi:10.1111/jam.12430

Desbois, A.P., 2012. Potential applications of antimicrobial fatty acids in medicine, agriculture and other industries. Recent patents on anti-infective drug discovery $7,111-122$.

Dombek, K.M. \& Ingram, L.O., 1986. Magnesium limitation and its role in apparent toxicity of ethanol during yeast fermentation. Appl. Environ. Microbiol. 52, 975-981.

Edwards, C.G., Reynolds, A.G., Rodriguez, A.V., Semon, M.J. \& Mills, J.M., 1999. Implication of acetic acid in the induction of slow/stuck grape juice fermentations and inhibition of yeast by Lactobacillus sp. Am. J. Enol. Vitic. 50, 204-210.

Fantozzi, P. \& Montedoro, G., 1974. Gaschromatographische Bestimmung der freien Aminosäuren in Most und Wein. Am. J. Enol. Vitic. 25, 151-156.

Fischer, U., 2000. Gärunterbrechungen und Behebung von Gärstörungen. ATW Bericht 97.

Fornairon-Bonnefond, C., Aguera, E., Deytieux, C., Sablayrolles, J.M. \& Salmon, J.M., 2003. Impact of oxygen addition during enological fermentation on sterol contents in yeast lees and their reactivity towards oxygen. $\mathrm{J}$ Biosci. Bioengin. 95, 496-503.
Guilloux-Benatier, M., Le Fur, Y. \& Feuillat, M., 1998. Influence of fatty acids on the growth of wine microorganisms Saccharomyces cerevisiae and Oenococcus oeni. J. Indus. Microbiol. Biotechnol. 20, 144-149.

Hervé, A. \& Guilloux-Benatier, M., 2006. Yeast autolysis in sparkling wine - A review. Aust. J. Grape and Wine Res. 12, 119-127.

Hou, C.T., 2008. New bioactive fatty acids. Asia Pacific J. Clin. Nutrit. 17, 192-195.

Ingledew, W.M. \& Kunkee, R.E., 1985. Factors influencing sluggish fermentations of grape juice. Am. J. Enol. Vitic. 36, 65-76.

Karlova, T., Polakova, L, Smidrkal, J. \& Filip, V., 2010. Antimicrobial effects of fatty acid fructose esters. Czech J. Food Sci. 28, 146-149.

Kliewer, W.M., 1970. Free amino acids and other nitrogenous fractions in wine grapes. J. Food Sci. 35, 17-21.

Kment, P., Mihaljevič, M., Ettler, V., Šebek, O., Strnad, L. \& Rohlová, L., 2005. Differentiation of Czech wines using multielement composition - A comparison with vineyard soil. Food Chem. 91, 157-165.

Kunze, W., 1998. Technologie Brauer und Mälzer. Verlag der VLB Berlin, Berlin.

Lafon-Lafourcade, S., Geneix, C. \& Ribéreau-Gayon, P., 1984. Inhibition of alcoholic fermentation of grape must by fatty acids produced by yeasts and their elimination by yeast ghosts. Appl. Environ. Microbiol. 47, 1246-1249.

Malherbe, S., Bauer, F.F. \& Du Toit, M., 2007. Understanding problem fermentations - A review. S. Afr. J. Enol. Vitic. 28, 169-186.

Nabais, R.C., Sá-Correia, I., Viegas, C.A. \& Novais, J.M., 1988. Influence of calcium ion on ethanol tolerance of Saccharomyces bayanus and alcoholic fermentation by yeasts. Appl. Environ. Microbiol. 54, 2439-2446.

Nel, H.A., Moes, C.J. \& Dicks, L.M.T., 2000. Sluggish/stuck malolactic fermentation in Chardonnay: Possible causes. Wynboer, A Technical Guide for Wine Producers.

Nicolini, G., Larcher, R., Pangrazzi, P. \& Bontempo, L., 2004. Changes in the contents of micro- and trace-elements in wine due to winemaking treatments. Vitis 43, 41-45.

Ramey, D., Bertrand, A., Ough, C.S., Singleton, V.L. \& Sanders, E., 1986. Effects of skin contact temperature on Chardonnay must and wine composition. Am. J. Enol. Vitic. 37, 99-106.

Rasmussen, J.E., Schultz, E., Snyder, R.E., Jones, R.S. \& Smith, C.R., 1995. Acetic acid as a causative agent in producing stuck fermentations. Am. J. Enol. Vitic. 46, 278-280. 
Ribéreau-Gayon, P., Glories, Y., Maujean, A. \& Dubourdieu, D., 2000. Handbook of enology. John Wiley \& Sons Ltd.: West Sussex, England.

Schmidt, K. \& Bayer, W., 1982. Mineralstoffwechsel und Abwehrsystem. Verlag für Medizin Dr. Ewald Fischer, Heidelberg.

Schobinger, U., 2001. Frucht- und Gemüsesäfte. Verlag Eugen Ulmer $\mathrm{GmbH} \& \mathrm{Co}$. , Stuttgart.

Schütz, M. \& Gafner, J., 1993. Sluggish alcoholic fermentation in relation to alterations of the glucose-fructose ratio. Chemie, Mikrobiologie, Technologie der Lebensmittel 15, 73-78.

Schütz, M. \& Gafner, J., 1996. Impact of glucose-fructose-ratio on stuck fermentations: Practical experiences to restart stuck fermentations. WeinWissenschaft 51, 214-218.
Viegas, C.A., Rosa, M.F., Sá-Correia, I. \& Novais, J.M., 1989. Inhibition of yeast growth by octanoic and decanoic acids produced during ethanolic fermentation Appl. Environ. Microbiol. 55, 21-28.

Walker, G.M., 2000. Yeast physiology and biotechnology. John Wiley \& Sons, West Sussex.

Würdig, G. \& Woller, R., 1989. Chemie des Weines. Verlag Eugen Ulmer $\mathrm{GmbH} \& \mathrm{Co}$, Stuttgart.

Zoecklein, B.W., Fugelsang, K.C., Gump, B.H. \& Nury, F.S., 1999. Wine analysis and production. Kluwer Academic/Plenum Publishers, New York. 